Article

\title{
Freeze Granulated Zeolites $X$ and A for Biogas Upgrading
}

\section{Kritika Narang(D) and Farid Akhtar*}

Division of Materials Science, Luleå University of Technology, 97187 Luleå, Sweden; kritika.narang@ltu.se

* Correspondence: farid.akhtar@ltu.se; Tel.: +0920-491793

Academic Editor: Susana Valencia

Received: 5 February 2020; Accepted: 11 March 2020; Published: 18 March 2020

\begin{abstract}
Biogas is a potential renewable energy resource that can reduce the current energy dependency on fossil fuels. The major limitation of utilizing biogas fully in the various applications is the presence of a significant volume fraction of carbon dioxide in biogas. Here, we used adsorption-driven $\mathrm{CO}_{2}$ separation using the most prominent adsorbents, $\mathrm{NaX}$ (faujasite) and $\mathrm{CaA}$ (Linde Type A) zeolites. The $\mathrm{NaX}$ and $\mathrm{CaA}$ zeolites were structured into hierarchically porous granules using a low-cost freeze granulation technique to achieve better mass transfer kinetics. The freeze granulation processing parameters and the rheological properties of suspensions were optimized to obtain homogenous granules of $\mathrm{NaX}$ and $\mathrm{CaA}$ zeolites 2-3 $\mathrm{mm}$ in diameter with macroporosity of $77.9 \%$ and $68.6 \%$, respectively. The $\mathrm{NaX}$ and $\mathrm{CaA}$ granules kept their individual morphologies, crystallinities with a $\mathrm{CO}_{2}$ uptake of $5.8 \mathrm{mmol} / \mathrm{g}$ and $4 \mathrm{mmol} / \mathrm{g}$, respectively. The $\mathrm{CO}_{2}$ separation performance and the kinetic behavior were estimated by breakthrough experiments, where the $\mathrm{NaX}$ zeolite showed a $16 \%$ higher $\mathrm{CO}_{2}$ uptake rate than $\mathrm{CaA}$ granules with a high mass transfer coefficient, $1.3 \mathrm{~m} / \mathrm{s}$, compared to commercial granules, suggesting that freeze-granulated zeolites could be used to improve adsorption kinetics and reduce cycle time for biogas upgrading in the adsorption swing technology.
\end{abstract}

Keywords: freeze granulation; zeolite $\mathrm{NaX}$; zeolite $\mathrm{CaA}$; gas separation; carbon dioxide capture

\section{Introduction}

Biogas offers a sustainable fuel to the environment as it contributes to low carbon emissions during its combustion. The raw biogas obtained from an anaerobic digester mainly consist of $\mathrm{CH}_{4}$ with $40-45 \% \mathrm{CO}_{2}$ including a minor content of impurities, such as water, siloxanes, ammonia and hydrogen sulfide $[1,2]$. Great efforts have been made in the biogas separation and purification technologies to procure biomethane with a low energy footprint [3,4]. The removal of $\mathrm{CO}_{2}$ from biogas increases the methane content to above $98 \mathrm{vol} \%$, which offers the use of upgraded biogas in natural gas grids and as a fuel for automotive industry [5]. The pressure swing adsorption technology (PSA) is one of the promising technologies for gas separation and production of gases used by industries [6-8]. In the context of biogas upgrading using the PSA technology, the structured adsorbent in the form of granules, pellets, laminates, and extrudates of zeolites, microporous silicates and activated carbon are utilized to separate $\mathrm{CO}_{2}$ from the biogas stream by exploiting equilibrium, kinetic, as well as size-selective adsorption strategies [9-11]. Zeolites are well-studied kinetically and thermodynamically for their $\mathrm{CO}_{2}$ separation from $\mathrm{CH}_{4}$ and $\mathrm{N}_{2}$, as they provide high volumetric $\mathrm{CO}_{2}$ adsorption capacity even at low $\mathrm{CO}_{2}$ partial pressure [12,13]. Zeolites $\mathrm{X}, \mathrm{A}$ and chabazite offer promising properties, such as remarkable selectivity of $\mathrm{CO}_{2}$ over $\mathrm{CH}_{4}$, high thermal stability, fast adsorption kinetics, and cyclic performance, which together reduce the energy penalty in the separation and purification process [14-16].

The $\mathrm{NaX}$ zeolite has a faujasite (FAU) type framework with sodalite cages comprised of $\mathrm{SiO}_{4}$ and $\mathrm{AlO}_{4}$ tetrahedra and connected through double six-rings to create a large super-cage cavity (aperture 
$0.74 \mathrm{~nm}$ ) [17]. The CaA zeolite has a Linde type A (LTA) structure where sodalite cages are connected through double four-rings and give rise to an alpha cavity (aperture $0.43 \mathrm{~nm}$ ) [17].

Zeolites are most often produced in the powder form; however, powder offers challenges, mainly in the pressure swing adsorption technology during the biogas cleaning-up process. Using porous materials in the powder form offers significant drawbacks, such as fluidization of the PSA column and high particle attrition rate, which further give rise to a high pressure drop within the column and thereby an increase in the maintenance cost and energy consumption of the PSA systems in addition to poor adsorption and regeneration of the adsorbent material $[18,19]$. Hence, there remains a need to structure the zeolite powders into mechanically stable hierarchically porous structures, such as granules, monoliths, honeycombs, laminates, etc., with favorable carbon capture kinetics to permit efficient $\mathrm{CO}_{2}$ separation from biogas. The structured zeolites provide high mass transfer, low pressure drop, better heat management in the adsorption columns in the PSA [18,20]. For instance, Wenjing Zhang et al. have designed hierarchical composite ZSM-5 pellets for biogas upgrading and achieved a $30 \%$ larger BET surface area with a $34 \%$ increase in $\mathrm{CO}_{2}$ uptake capacity for the hierarchically structured porous zeolite [21].

Structuring of the zeolites into granules and beads is a simple and facile approach for improving flowability, mechanical strength, $\mathrm{CO}_{2}$ separation performance, rapid mass transfer kinetics, and to facilitate high $\mathrm{CO}_{2}$ uptake. The small granule size is preferred to obtain high mass transfer kinetics with low void fraction to improve the carbon-capturing efficiency; however, small size granules also give rise to a high pressure drop in the PSA unit $[18,22,23]$. Therefore, granules' characteristics must be optimized in a way to facilitate control over granular size, density, and macroporosity. In recent years, reverse wet granulation, foam granulation, thermal adhesion granulation, spray drying, freeze granulation, and sieve granulation have been used to granulate powders [18,24]. Freeze granulation is a recently developed method for granulation that has shown ideal characteristics of the granulation process by providing homogeneous spherical granules with a uniform size and improved flowability. Freeze granulation process provides a versatile approach in introducing hierarchical porous structures with the ability to control pore size, morphology, and orientation. Control over the freezing rate can offer modulation in ice-templating during the freeze granulation process to provide high open porosity in the structured adsorbents [25]. It is beneficial to use the freeze-drying process as the ice sublimes leaving structured material with continuous residual ice template pores and results in homogenous granules. Freeze granulation has previously been used to process metal, metal oxide, and ceramic powders industrially for applications as transparent ceramics and in the pharmaceutical sector [26]. Suitable inorganic and organic binders are used to increase the mechanical strength of the granules. Raksh V. Jasra et al. have shown the effect of binders on the sorption properties of $\mathrm{Y}$ and mordenite zeolites and observed a 34-78\% increase in the heat of adsorption for $\mathrm{N}_{2}$ in the respective structured zeolites [27]. Similarly, Charkhi Amir et al. have studied the effects of bentonite on the adsorption properties of the granulated $\mathrm{NaY}$ nanozeolite and showed that the increase in the bentonite content in the zeolite led to the reduction in the BET surface area [28]. Therefore, the type and amount of the binder can crucially affect the rheological characteristics of the suspension and the adsorptive properties of the structured zeolite [29]. Recently, M. Ouadaker et al. have prepared the porous granules of the Pickering emulsions stabilized with the halloysite mineral. They investigated such characteristics of the porous granules as morphology, size stability, strength, and porosity by varying the $\mathrm{pH}$ and ionic strength of the suspensions, and also showed that addition of organic binders, such as polyvinyl alcohol and polyethylene glycol, increases cohesion of the emulsions and leads to highly structured materials [29].

In the freeze granulation process, granules are instantly frozen in liquid nitrogen $\left(-196{ }^{\circ} \mathrm{C}\right)$ and subjected to the freeze-drying process. This fast freezing process prevents migration of the constituents due to the limitations of the diffusion dynamics, thereby permitting production of homogenously structured granules. Migration of the constituents in the granulation process has been observed in other granulation techniques, such as spray drying, and it leads to non-homogeneous 
granules [30]. Furthermore, water-templating during the freeze granulation process creates additional macroporosity to offer additional mass transfer pathways to achieve superior mass transfer kinetics in the adsorption/desorption process [25,31,32]. Lyckfeldt et al. have shown that freeze granulation is a suitable alternative to the conventional granulation for processing the $\mathrm{Si}_{3} \mathrm{~N}_{4}$ materials into spherical and free-flowing granules [33]. S.J. Milne studied the influence of different drying conditions on the powder properties and processing characteristics and concluded that freeze-drying led to a lower degree of agglomeration [34]. The research on the granulation of zeolites to produce hierarchical zeolite granules with optimum properties is still sparse. However, in this study, we have freeze-granulated $\mathrm{NaX}$ and $\mathrm{CaA}$ zeolites to investigate their carbon-capturing properties as regards to the $\mathrm{CO}_{2}$ and $\mathrm{CH}_{4}$ gas mixture.

In this work, we have optimized the design of highly porous granules with a hierarchy of pores from zeolite $\mathrm{NaX}$ and $\mathrm{CaA}$ powders using a low-cost robust freeze granulation approach, and evaluated the granules in terms of $\mathrm{CO}_{2}$ separation from $\mathrm{CH}_{4}$. Prior to the freeze granulation process, the zeolite suspension characteristics were investigated. The stable colloidal zeolite suspensions consisting of zeolite powder, bentonite clay, polyethylene glycol, polyacrylic acid, and water were prepared, and the optimum stirring rate was set up following the rheology data to achieve feasible viscosity for freeze granulation of highly porous granules. The granules were investigated for their $\mathrm{CO}_{2}$ and $\mathrm{CH}_{4}$ adsorption characteristics with their mass transfer kinetics.

\section{Results and Discussion}

The granules of zeolites $\mathrm{NaX}$ and $\mathrm{CaA}, 2-3 \mathrm{~mm}$ in diameter were successfully produced using the freeze granulation process. The rheological behavior of the deagglomerated $\mathrm{NaX}$ and $\mathrm{CaA}$ suspensions prior to freeze granulation is shown in Figure 1. The solid content of the suspensions was calculated to obtain $70 \%$ macroporosity from water-templating in the granules. It can be seen in Figure 1 that zeolite suspensions exhibit the shear thinning behavior; the apparent viscosity decreases with the increase in the shear rate. It has been reported that zeolite-water suspensions show the Newtonian behavior, and it changes to the non-Newtonian one on changing either the $\mathrm{pH}$ of the suspension or with the addition of clay particles with the plate-like morphology [35-37]. In this work, the shear thinning behavior is due to the presence of the inorganic clay binder bentonite [35]. Bentonite is a widely available clay binder for the zeolites with wet binding characteristics to structure zeolites in hierarchical porous advanced materials. The suspension shows colloidal stability when the shear rate increases to and over $250 \mathrm{~s}^{-1}$. The colloidal stability of the zeolite-bentonite suspension was achieved due to the presence of the negative surface charge on the bentonite, as well as on zeolites $\mathrm{NaX}$ and $\mathrm{CaA}$ at the alkaline $\mathrm{pH}$ of 9.6. The $\mathrm{pH}$ of the formed suspensions was alkaline and gave rise to the negative surface charge, as the isoelectronic points of bentonite and zeolite are 8.0 and 4.7, respectively; this ensures electrostatically stabilized suspensions with good electrostatic dispersion of the particles [18,38,39].

To achieve a feasible flow for the granulation procedure, the shear rate of $355 \mathrm{~s}^{-1}$ was considered for the $\mathrm{NaX}$ suspension, as well as for the CaA suspension, and the stirring rate was calculated according to Equation (1) [40].

$$
\gamma=4 * \pi * n /\left(1-k^{2}\right)
$$

where the shear rate is related to the stirring frequency $n$ and the geometric parameters of the stirring setup $k$, which is defined as the ratio between the magnetic stirrer length and the diameter of the beaker used. The magnetic stirrer length and cylindrical beaker diameter were $4.2 \mathrm{~cm}$ and $5 \mathrm{~cm}$, respectively. The stirring frequency was calculated to be $500 \mathrm{rpm}$ for both the suspensions to ensure a feasible flow and dispersibility of suspensions in the granulation process. 


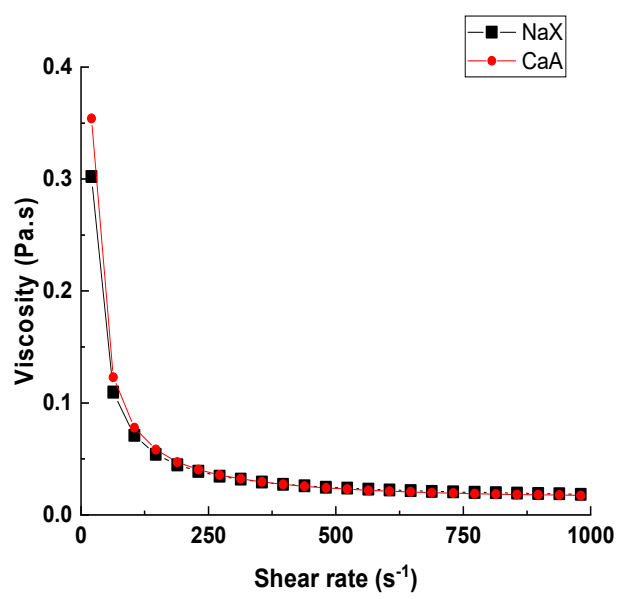

Figure 1. Viscosity as a function of the shear rate of the NaX suspension (black) and the CaA suspension (red) containing zeolite, bentonite, PEG (polyethylene glycol), PAA (polyacrylic acid), and water.

The morphology of the $\mathrm{NaX}$ and $\mathrm{CaA}$ zeolite granules with the inset of the whole granule is presented in Figure 2a,b. The granules exhibit spherical shape and possess a high degree of macroporosity ( $77.9 \%$ for $\mathrm{NaX}$ granules and $68.6 \%$ for CaA granules) determined using mercury intrusion porosimetry in Figure 2c, with a zeolite particle size from 2.5 to 4.5 microns for NaX granules and 2.5 to 4.0 microns for CaA granules. After the heat treatment, the original morphology of both the zeolite particles was intact, which implies that neither granulation nor freeze-drying or thermal treatment has any significant influence on the morphology of the starting zeolites.

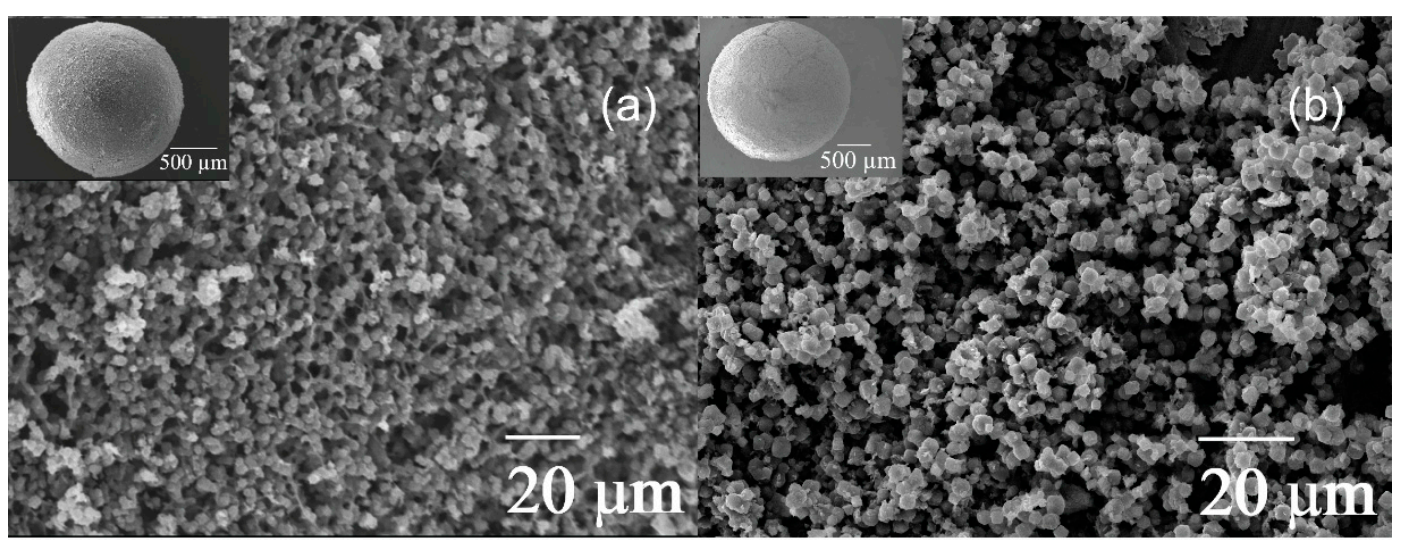

(c)

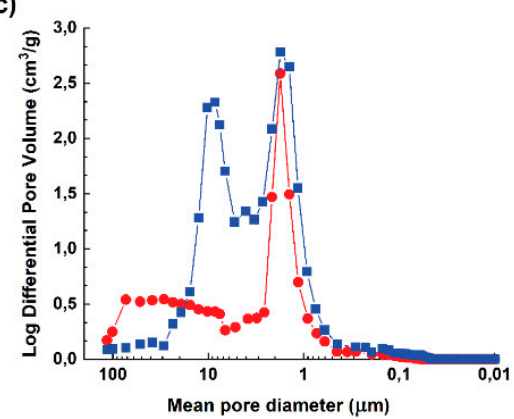

Figure 2. (a) Scanning electron micrograph of $\mathrm{NaX}$ granules with the inset of a single NaX granule; (b) Scanning electron micrograph of CaA granules with the inset of a single CaA granule; (c) Mercury intrusion porosimetry data for $\mathrm{NaX}$ granules (blue, square) and $\mathrm{CaA}$ granules (red, circle).

The CaA granules show the pore size with the mean pore diameter of $1.7 \mu \mathrm{m}$, while NaX granules show bimodal pore size distribution with the mean pore diameter of $1.7 \mu \mathrm{m}$ and $8.6 \mu \mathrm{m}$ (Figure 2c). 
The mean pore diameter of $1.7 \mu \mathrm{m}$ for both $\mathrm{NaX}$ and $\mathrm{CaA}$ granules describes the inter-pore distance between particles within the granules. In the case of $\mathrm{NaX}$ granules, the mean pore diameter of $8.6 \mu \mathrm{m}$ obtained by ice-templating implies the existence of large inter-particle voids between the NaX particles within the granules formed during freeze-drying, which involves the sublimation of ice leaving behind large ice-template voids. Mercury intrusion porosimetry data show good agreement with the SEM micrographs presented in Figure 2a,b, which also display large inter-particle voids between the particles. The $\mathrm{CaA}$ granules showed ice-templating pores with a broad pore size distribution from ca. 6.5 to $102 \mu \mathrm{m}$. The reason for this broad distribution might be associated with the significant aeration in the CaA suspensions associated with a larger external surface area (Table 1), which ultimately leads to these large voids with trapped air in them.

Table 1. A summary of textural properties of freeze-granulated zeolites and powders.

\begin{tabular}{|c|c|c|c|c|}
\hline Sample Name & $\begin{array}{c}\text { BET } \\
\text { Surface Area } \\
\left(\mathrm{m}^{2} / \mathrm{g}\right)\end{array}$ & $\begin{array}{l}\text { Micropore Area } \\
\left(\mathrm{m}^{2} / \mathrm{g}\right)\end{array}$ & $\begin{array}{c}\text { External } \\
\text { Surface Area } \\
\left(\mathrm{m}^{2} / \mathrm{g}\right)\end{array}$ & $\begin{array}{c}\text { Micropore } \\
\text { Volume } \\
\left(\mathrm{cm}^{3} / \mathrm{g}\right)\end{array}$ \\
\hline CaA powder & 528 & 441 & 86 & 0.21 \\
\hline CaA granules & 411 & 351 & 60 & 0.18 \\
\hline NaX powder & 685 & 644 & 41 & 0.35 \\
\hline $\mathrm{NaX}$ granules & 557 & 513 & 43 & 0.25 \\
\hline
\end{tabular}

Structuring the granules from the freeze granulation process followed by pressureless thermal treatment does not affect the crystal structure as verified by XRD patterns of calcined $\mathrm{NaX}$ and $\mathrm{CaA}$ granules in Figure 3a,b. The XRD patterns of granules correspond well with the XRD pattern of the starting zeolite powder, indicating that the freeze granulation process as well as the thermal treatment at $700{ }^{\circ} \mathrm{C}$ keep the crystallinity of the structured zeolites.

(a)

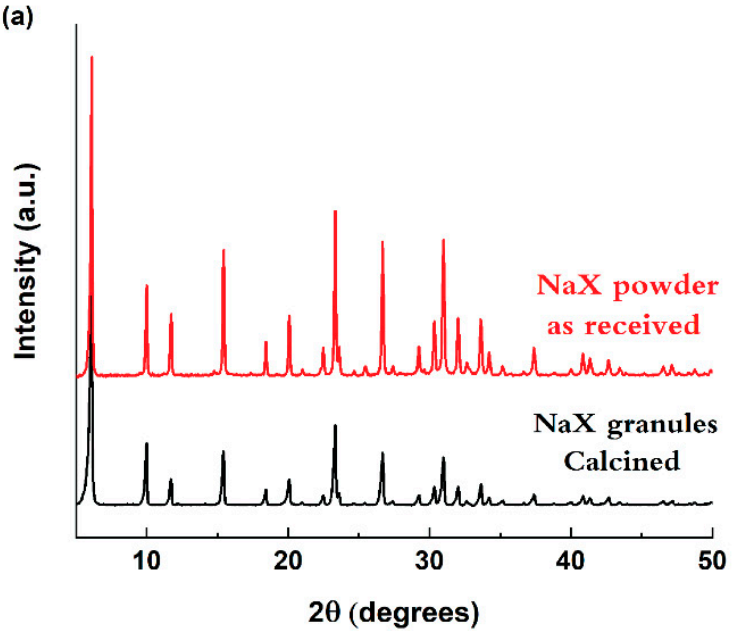

(b)

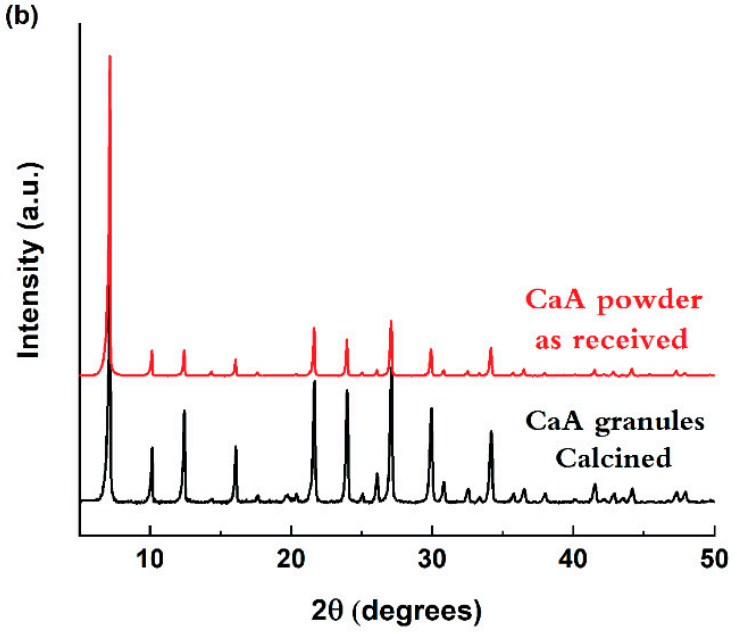

Figure 3. (a) XRD pattern of the NaX powder (above, red) and NaX granules (below, black); (b) XRD pattern of the CaA powder (above, red) and CaA granules (below, black). The NaX granules pattern matched the Faujasite (FAU) type framework, PDF card no. 00-0380237, and CaA granules pattern matched the Linde Type A (LTA), PDF card no. 01-073-9561.

The textural properties of the zeolite $\mathrm{NaX}$ and $\mathrm{CaA}$ granules and powders are summarized in Table 1. The specific BET surface area has shown a decrease of $18.6 \%$ for the NaX granules and $22 \%$ for the CaA granules as compared to the starting zeolite powders. The active component in the fabricated granules is diluted due to the presence of an inactive bentonite binder, thereby resulting in a decrease in specific surface area. Another reason for this reduction is attributed to the blocking of micropores by the bentonite clay on binding zeolite crystals, which results in the lowering of adsorbed $\mathrm{N}_{2}$ per gram 
of granules. According to Amir Chakri et al., the increment of bentonite clay from 20 to $40 \mathrm{wt} \%$ in the granulated NaY nanozeolite can enhance the blocking of micropores and decrease the BET surface area by $66 \%$ [28]. The external surface area of the CaA powder is greater than of the NaX powder, which supports the hypothesis of a considerably higher aeration in the CaA suspension.

Figure 4 represents the adsorption isotherms of $\mathrm{CO}_{2}$ and $\mathrm{CH}_{4}$ for both $\mathrm{NaX}$ and $\mathrm{CaA}$ granules at $273 \mathrm{~K}$ and $293 \mathrm{~K}$. The $\mathrm{CO}_{2}$ adsorption isotherm falls into the IUPAC type I isotherm [41] indicating that the material features microporosity. Zeolites $\mathrm{NaX}$ and $\mathrm{CaA}$ have high $\mathrm{CO}_{2}$ adsorption capacity due to the strong electrostatic interactions of the surface of the ionic aluminosilicate micropore cages and the quadrupole moment of $\mathrm{CO}_{2}$; whereas at the same time, the $\mathrm{CH}_{4}$ adsorption isotherm is a linear isotherm showing a weak interaction between the zeolite and the $\mathrm{CH}_{4}$ due to the absence of the quadrupole moment resulting in low adsorption capacities [42]. The $\mathrm{CO}_{2}$ uptake capacity increases from 5.09 to $5.80 \mathrm{mmol} / \mathrm{g}$ from $293 \mathrm{~K}$ to $273 \mathrm{~K}$, respectively, for the NaX granules. As the adsorption process is exothermic, a decrease in temperature will provide insufficient kinetic energy to gas molecules to desorb from the adsorbent, therefore, reduction in temperature enhances the uptake capacity. Furthermore, it was noticed that the difference in the $\mathrm{CO}_{2}$ uptake capacities for the CaA granules at $293 \mathrm{~K}$ and $273 \mathrm{~K}$ is not significant. The methane uptake was almost similar for both the granules. $\mathrm{NaX}$ granules have a higher $\mathrm{CO}_{2}$ uptake than $\mathrm{CaA}$ granules, and their corresponding powder zeolites show the same trend of adsorption as shown in Figure 4. Zeolite NaX powders have a higher $\mathrm{CO}_{2}$ uptake capacity than the zeolite $\mathrm{CaA}$ powder due to the higher specific BET surface area and pore volume of zeolite $\mathrm{NaX}$ [43]. The $\mathrm{CO}_{2}$ uptake capacity at $293 \mathrm{~K}$ of $\mathrm{NaX}$ and $\mathrm{CaA}$ granules is lower than their respective powders as shown in Figure 4. The zeolite particles in the granules contain an inorganic binder to impart additional strength to the granules. However, the binder dilutes the active component (zeolite) in granules per unit mass as compared to the pure NaX and CaA powders; this corresponds to the reduction in the $\mathrm{CO}_{2}$ adsorption capacity. Similar results were shown by Ojuva A. et al., where zeolite $13 \mathrm{X}$ powders were structured into monoliths using freeze casting to provide hierarchical porosity and observed a similar reduction in the $\mathrm{CO}_{2}$ adsorption capacity due to the presence of an inorganic binder [35].

(a)

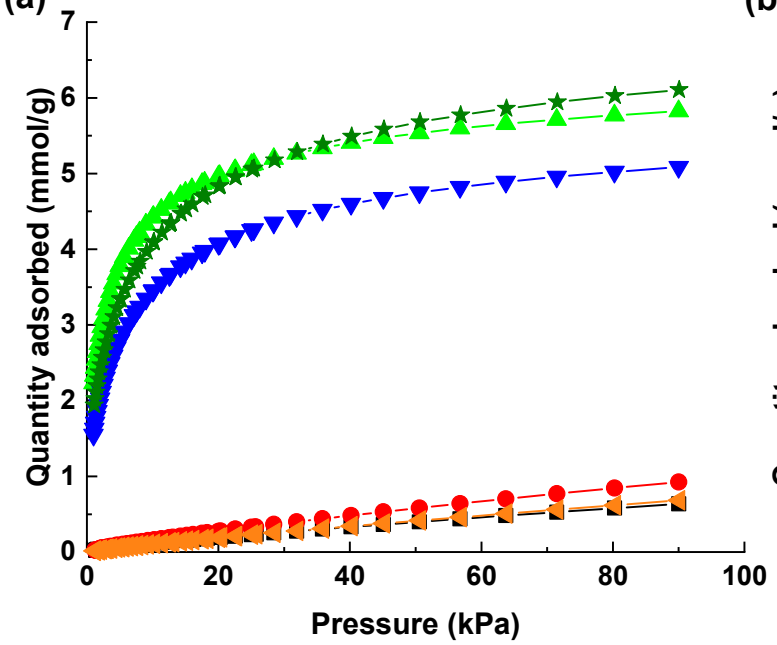

(b)

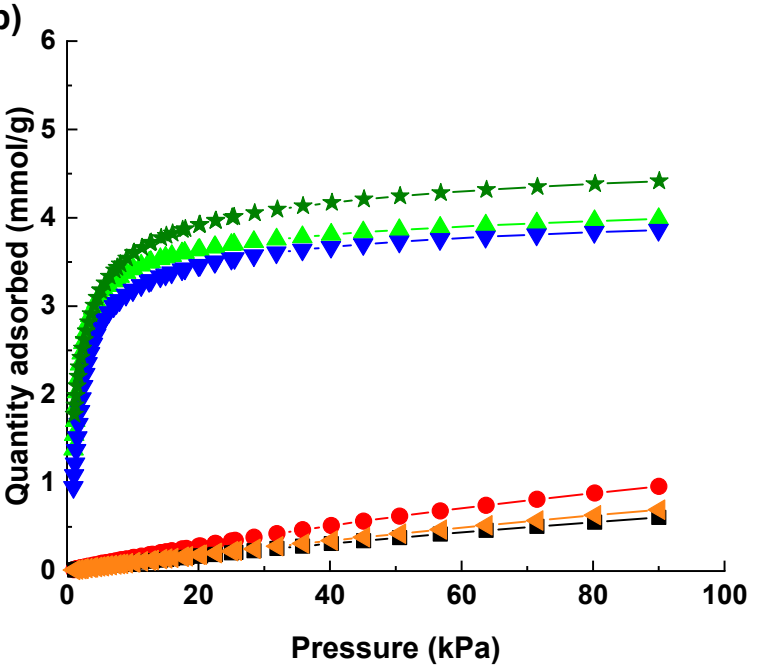

Figure 4. (a) $\mathrm{CO}_{2}$ adsorption isotherm (top) for $\mathrm{NaX}$ : for granules at $273 \mathrm{~K}$ (triangles) and at $293 \mathrm{~K}$ (inverted triangles), for the powder at $293 \mathrm{~K}$ (stars); $\mathrm{CH}_{4}$ adsorption isotherm (bottom) for $\mathrm{NaX}$ : for granules at $273 \mathrm{~K}$ (circles) and at $293 \mathrm{~K}$ (squares), for the powder at $293 \mathrm{~K}$ (rotated triangles); (b) $\mathrm{CO}_{2}$ adsorption isotherm (top) for CaA: for granules at $273 \mathrm{~K}$ (triangles) and at $293 \mathrm{~K}$ (inverted triangles), for the powder at $293 \mathrm{~K}$ (stars); $\mathrm{CH}_{4}$ adsorption isotherm (bottom) for CaA: for granules at $273 \mathrm{~K}$ (circles) and at $293 \mathrm{~K}$ (squares), and for the powder at $293 \mathrm{~K}$ (rotated triangles). 
The $\mathrm{CO}_{2}$ uptake capacity for the $\mathrm{NaX}$ and $\mathrm{CaA}$ granules is higher than the previously reported 3D-printed $\mathrm{NaX}$ and $\mathrm{CaA}$ zeolite monoliths [44]. The $\mathrm{CO}_{2}$ uptake of freeze-granulated $\mathrm{NaX}$ was $14 \%$ higher than of the structured $\mathrm{NaX}$ beads as reported by Fateme Rezaei et al. [45]. Similarly, the $\mathrm{CO}_{2}$ uptake of freeze-granulated CaA was 100\% higher than of the granulated CaA zeolite reported by Leonel G. et al., where the granulation approach used was nucleation and further consolidation [46]. The $\mathrm{CO}_{2}$ adsorption capacity of the freeze-granulated $\mathrm{NaX}$ zeolite is comparable to the $\mathrm{NaX}$ monolith prepared by freeze casting [35]. Furthermore, the $\mathrm{CO}_{2}$ separation performance was investigated by determining the $\mathrm{CO}_{2}$-over- $\mathrm{CH}_{4}$ selectivity using the Henry's law. $\mathrm{NaX}$ granules have a higher $\mathrm{CO}_{2}$-over- $\mathrm{CH}_{4}$ selectivity of 214 , whereas $\mathrm{CaA}$ granules showed the $\mathrm{CO}_{2}$-over- $\mathrm{CH}_{4}$ selectivity of 172 at $273 \mathrm{~K}$. It is established that selectivity and gas adsorption characteristics of zeolites can be tailored using ion exchange in zeolites [43]. Studies on the cation exchange from $\mathrm{Na}^{+}$to $\mathrm{Ca}^{2+}$ in the $\mathrm{X}$ zeolite, or from $\mathrm{Ca}^{2+}$ to $\mathrm{Na}^{+}$in the A zeolite have been conducted to tune the gas adsorption capacity and selectivity [47-49]. S. Chen et al. have recently shown the increase in the $\mathrm{CO}_{2}$ uptake after the ion exchange of $\mathrm{Na}^{+}$cations with $\mathrm{Ca}^{2+}$ cations at different concentrations [50].

Figure 5 shows the cyclic breakthrough experiments on $\mathrm{NaX}$ and $\mathrm{CaA}$ granules to determine the adsorption and mass transfer kinetic parameters. In a breakthrough curve, $\mathrm{C} / \mathrm{C}_{0}$ represents the relative concentration of $\mathrm{CO}_{2}$, where $\mathrm{C}$ and $\mathrm{C}_{0}$ correspond to the concentration at the outlet and the inlet of the fixed bed, respectively. The relative concentration of zero in the breakthrough curve means that all the $\mathrm{CO}_{2}$ gas molecules are being adsorbed, whereas the relative concentration of one implies that the saturation of the bed has been achieved. The zone between zero to one is described as the mass transfer zone, where most of the mass transfer takes place [51]. Both curves offer the same breakthrough width, which is defined as the time difference to attain $5 \%$ and $95 \%$ of the final concentration of $\mathrm{CO}_{2}$, which implies that the gas velocity is uniform in both the columns containing $\mathrm{NaX}$ and $\mathrm{CaA}$ granules [52]. Stability was achieved after a few cycles of the breakthrough experiment as shown in Figure 5a,b. The CaA granules were able to attain stability faster than the NaX granules. The reduction in the breakthrough point was observed on both curves after cycle 1 due to the presence of unreleased chemisorbed $\mathrm{CO}_{2}$ even after performing regeneration by evacuation. The amount of the $\mathrm{CO}_{2}$ gas adsorbed by $\mathrm{NaX}$ and $\mathrm{CaA}$ was $5.7 \mathrm{mmol} / \mathrm{g}$ and $5.1 \mathrm{mmol} / \mathrm{g}$, respectively, for cycle 1 , and it reduced to $4.9 \mathrm{mmol} / \mathrm{g}$ and $4.2 \mathrm{mmol} / \mathrm{g}$ for the $\mathrm{NaX}$ and CaA granules, respectively, in cycle 5 . This reduction in capacity with cycles can be attributed to the chemisorbed $\mathrm{CO}_{2}$ in the granules that were not able to evacuate completely or to an inefficient evacuation technique. The $\mathrm{CO}_{2}$ uptake rate for the stable cycle was $3.6 \mathrm{mg}$ of $\mathrm{CO}_{2} / \mathrm{g} / \mathrm{s}$ and $3.1 \mathrm{mg}$ of $\mathrm{CO}_{2} / \mathrm{g} / \mathrm{s}$ for $\mathrm{NaX}$ and $\mathrm{CaA}$ granules, respectively. The $\mathrm{CO}_{2}$ adsorption rate was higher than the one previously reported for $\mathrm{NaX}$ and $\mathrm{CaA}$ binderless beads [43]. Additionally, the granules were intact without any breakage after 5 adsorption-desorption cycles at 4 bar; this further enhanced the usability of freeze granules in the PSA for $\mathrm{CO}_{2}$ separation.
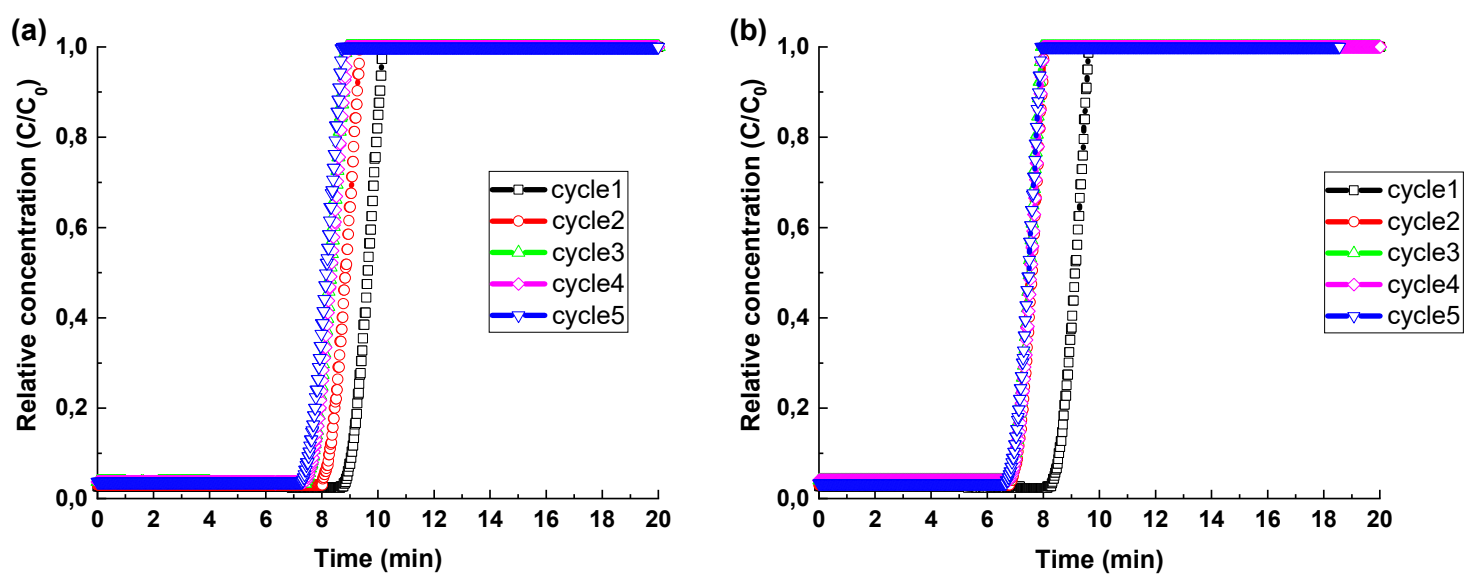

Figure 5. $\mathrm{CO}_{2}$ cyclic breakthrough measurements on (a) NaX granules; (b) CaA granules ( $\square$ black—cycle $1, \bigcirc$ red-cycle $2, \Delta$ green-cycle $3, \diamond$ pink—cycle $4, \nabla$ blue-cycle 5$)$. 
Breakthrough curves in Figure 5a,b have a sharp mass transfer zone that implies that these granules offer low mass transfer resistance with even gas flows within the column. The mass transfer coefficient was evaluated using the Klinkenberg Equation (2).

$$
C / C_{0}=1 / 2 \times \operatorname{erfc}(7 \sqrt{\xi} / 8-9 \sqrt{\tau} / 8)
$$

where $\xi$ and $\tau$ are defined as the dimensionless length and dimensionless time given by Equations (3) and (4), respectively. Parameter $\kappa$ is the mass transfer coefficient, $K$ is Henry's law constant of the adsorbate, $z$ is bed length, $\epsilon$ is total void fraction, $t$ is time in minutes, and $v$ is interstitial velocity given by Equation (5), where $Q_{V}$ is the volumetric flow rate of the gas and $S$ is the cross-sectional surface area of the bed.

$$
\begin{gathered}
\xi=\kappa K z((1-\epsilon) / v \epsilon \\
\tau=\kappa(t-z / v) \\
v=Q_{V} \epsilon / S
\end{gathered}
$$

Equation (2) was fitted to the experimental breakthrough data to simulate values of mass transfer coefficients. The mass transfer coefficient $(\kappa)$ is 1.3 and $1.6 \mathrm{~m} / \mathrm{s}$ for the NaX and CaA granules, respectively, higher than the one previously reported for a freeze-cast zeolite A monolith [53]. The mass transfer coefficient of freeze-granulated $\mathrm{NaX}$ and $\mathrm{CaA}$ is $29 \%$ and $166 \%$ higher than of the commercial binderless zeolite $\mathrm{NaX}$ and $\mathrm{CaA}$ granules (see supplementary information), respectively, as reported in our previous work. The higher mass transfer coefficient for CaA granules is due to the presence of large macropores created by ice-templating as confirmed from SEM and mercury intrusion porosimetry. However, these large networks of voids in the CaA granules may limit the available surface area and pore volume for the fluid to reach sufficient adsorption capacities.

\section{Materials and Methods}

\subsection{Chemicals and Procedures}

Zeolites $\mathrm{NaX}$ and $\mathrm{CaA}$ were purchased as powders with a particle size of $2-4 \mu \mathrm{m}$ from Luoyang Jianlong Chemical Industry Co., Ltd (Yanshi, Henan, China). Bentonite clay, polyethylene glycol (PEG, MW 300), and polyacrylic acid (PAA, MW 50) were purchased from Sigma-Aldrich Chemie GmbH (Buchs, Germany), Merck Schuchardt OHG (Hohenbrunn, Germany), and Polysciences, Inc. (Warrington, PA, USA), respectively.

The suspensions of zeolite $\mathrm{NaX}$ and $\mathrm{CaA}$ were prepared by dispersing $20 \mathrm{wt} \%$ of zeolite powder in $71 \mathrm{~mL}$ distilled water followed by magnetic stirring for $15 \mathrm{~min}$. Bentonite clay (3 $\mathrm{wt} \%)$ as an inorganic binder, water-soluble PEG (4 wt\%), and PAA (2 wt \%) as a sacrificial organic binder were added to the suspensions. The zeolite suspensions were placed on a magnetic stirrer overnight at room temperature for attaining homogeneous deagglomerated slurries. A PowderPro AB laboratory-scale granulator LS-6 (Sweden) equipped with a Watson-Marlow Bredel pump (England) was used for granulation. Figure 6 shows the freeze granulation process, including the resulting granules.

In the freeze granulation process, the homogeneous suspension was drawn by a suction tube using a pump at $30 \mathrm{rpm}$ into a spray nozzle $0.7 \mathrm{~mm}$ in diameter. To avoid clogging of the spray nozzle by undissolved additives or agglomerates, the suspensions were subjected to continuous stirring at a rate of $500 \mathrm{rpm}$ by a magnetic stirrer. The zeolite $\mathrm{NaX}$ and $\mathrm{CaA}$ suspensions were sprayed at an airflow of 0.19 bar and 0.17 bar, respectively, into the liquid nitrogen vessel to freeze the droplets instantaneously. The frozen granules were recovered in an aluminum tray and dried in a freeze dryer at $-110{ }^{\circ} \mathrm{C}$ for $72 \mathrm{~h}$ under vacuum. After the freeze-drying process, the granules were subjected to the thermal treatment at a heating rate of $1^{\circ} \mathrm{C} / \mathrm{min}$ up to $700{ }^{\circ} \mathrm{C}$. The thermal treatment was carried out in a N11/HR/P300 (Nabertherm GmbH, Germany) annealing and hardening furnace with a temperature control accuracy of $\pm 1^{\circ} \mathrm{C}$ and temperature uniformity of $\pm 5^{\circ} \mathrm{C}$. This thermal treatment was performed 
to remove temporary additives, such as PEG and PAA, and to strengthen the granules with the inorganic bentonite binder.

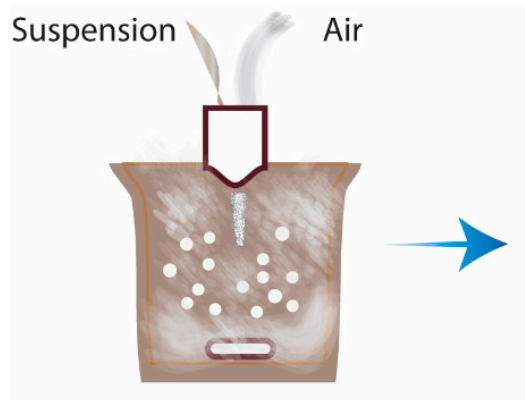

Freeze granulation

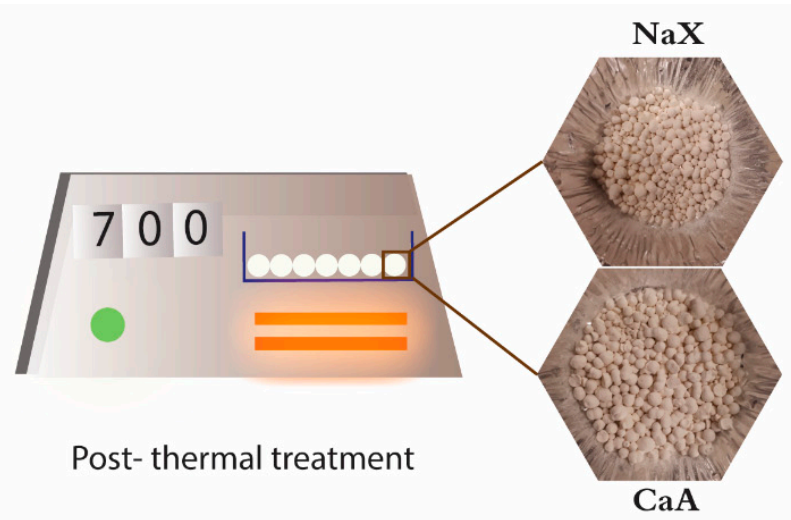

Figure 6. Schematic representation of the freeze granulation process with the resulting structured freeze granules.

\subsection{Characterization}

The $\mathrm{pH}$ of the suspensions was measured using an HI 1110 Hanna benchtop pH meter (Woonsocket, RI, USA) prior to the freeze granulation process.

The viscosity measurements for aqueous $\mathrm{NaX}$ and $\mathrm{CaA}$ suspensions (prepared as described above) were performed at $293 \mathrm{~K}$ using a Discovery Hybrid Rheometer DHR-2 (TA Instruments, New Castle, DE, USA) using standard rotational mapping geometry with a $20 \mathrm{~mm}$ parallel Peltier plate. Prior to the measurement, the suspensions were stirred overnight for attaining homogenous mixtures and to avoid sedimentation. The shear rate varied from 20 up to $1000 \mathrm{~s}^{-1}$ for NaX and CaA rheology measurements.

Powder X-ray diffraction patterns were recorded for as received $\mathrm{NaX}$ and $\mathrm{CaA}$ zeolite powders and structured granules over the $2 \theta$ range between $5^{\circ}$ to $70^{\circ}$ with a step size of $0.02^{\circ}$ using a PANalytical Empyrean instrument (Malvern, UK) equipped with a PIXcel 3D detector using $\mathrm{Cu} \mathrm{K} \alpha$ radiation (wavelength $0.154 \mathrm{~nm}$ ) at $40 \mathrm{kV}$ and $45 \mathrm{~mA}$. The investigated materials were grounded in a mortar and mounted on a stainless steel sample holder.

Scanning electron microscope micrographs were obtained using a JEOL JSM-IT300 microscope (Tokyo, Japan) operating at the acceleration voltage of $15 \mathrm{kV}$. The granules were crushed into powders and spread over a carbon tape. For obtaining micrographs of whole granules, a silver paste was used to hold granules on the sample holder. All the samples were subjected to gold sputtering before mounting on the sample holder to avoid any radiation damage and charging effect.

The surface area of the granules was determined using a micrometric Gemini VII 2390 Surface Area Analyzer (Micromeritics, Norcross, GA, USA) in the relative pressure (p/p $\mathrm{p}_{0}$ ) range of $0.05-0.35$ using the Brunauer-Emmett-Teller adsorption theory. Prior to the experiments, the samples were degassed under high vacuum $\left(1 \times 10^{-4} \mathrm{~Pa}\right)$ at $573 \mathrm{~K}$ overnight. The textural properties of the structured zeolite granules were evaluated using $\mathrm{N}_{2}$ adsorption experiments. The $\mathrm{N}_{2}$ adsorption experiments were carried out at $77 \mathrm{~K}$ using liquid nitrogen. Apart from the surface area determination, $\mathrm{CO}_{2}$ and $\mathrm{CH}_{4}$ adsorption isotherms were collected at $293 \mathrm{~K}$ and $273 \mathrm{~K}$ up to $100 \mathrm{kPa}$ pressure for all the samples. The temperature was maintained in an isothermal Dewar flask using an external thermometer.

Mercury intrusion porosimetry was carried out using a Micromeritics AutoPore III-9400 instrument (Norcross, GA, USA) across a wide pressure range (0.03-420 MPa) to access the mesopores and macropores. The pore size distribution was estimated using the Washburn Equation (6), which describes the relationship between the pressures needed to intrude mercury into the capillary pores of radius $r$, where $\gamma$ is the surface tension of $0.485 \mathrm{~N} / \mathrm{m}$ and $\theta$ is the contact angle of mercury of $130^{\circ}$.

$$
p=-2 \gamma \cos \theta / r
$$


Breakthrough experiments were performed on the freeze-granulated zeolites using a Pressure Swing Adsorption PSA-300LC instrument (L\&C Science and Technology, Hialeah, FL, USA). The $\mathrm{CO}_{2}$ separation performance was investigated at $293 \mathrm{~K}$ and 4 bar for up to 5 cycles. The flow rate was set to $75 \mathrm{~mL} / \mathrm{min}$ and $60 \mathrm{~mL} / \mathrm{min}$ for $\mathrm{CH}_{4}$ and $\mathrm{CO}_{2}$ gases, respectively, and the binary mixture was passed through a $100 \mathrm{~mm}$ long and $15 \mathrm{~mm}$ wide fixed bed. Prior to the breakthrough experiments, the samples were regenerated at $473 \mathrm{~K}$ under the inert helium flow of $20 \mathrm{~mL} / \mathrm{min}$ for $12 \mathrm{~h}$. To ensure significant drying of the granules, the dew point of $-18{ }^{\circ} \mathrm{C}$ was used as the standard. The amounts of the $\mathrm{NaX}$ and $\mathrm{CaA}$ freeze granules loaded in the bed were $4.4 \mathrm{~g}$ and $4.6 \mathrm{~g}$, respectively. The breakthrough curves were determined by setting up relative concentration $\left(C / C_{0}\right)$ as the vertical axis and time as the horizontal axis, where $C$ stands for the outlet concentration, and $C_{0}$ is the initial concentration of the gaseous mixture.

\section{Conclusions}

$\mathrm{NaX}$ and $\mathrm{CaA}$ zeolite powders were structured into the hierarchically porous granules by optimizing the freeze granulation process parameters and suspension rheology to display efficient $\mathrm{CO}_{2}$ separation performance. Stable colloidal suspensions of zeolites were prepared with the optimum amount of bentonite featuring weak shear thinning rheological behavior to obtain the deagglomerated and feasible flow required for the freeze granulation procedure. The freeze granulation process yielded homogenous granules of about $2-3 \mathrm{~mm}$ in diameter without affecting zeolite crystallinity and morphology. Furthermore, pressureless thermal treatment was carried out to remove temporary additives and improved the mechanical stability of the granules to withstand rapid pressure swings. The NaX granules show the $\mathrm{CO}_{2}$ uptake of $5.8 \mathrm{mmol} / \mathrm{g}$ at $273 \mathrm{~K}, 45 \%$ higher than the CaA granules. The sharp front in the adsorption-desorption cyclic breakthrough experiment implies that the granules offer low mass transfer resistance. The NaX granules showed high $\mathrm{CO}_{2}$-over- $\mathrm{CH}_{4}$ selectivity of 214 as compared to the CaA granules as calculated using the Henry's law. The mass transfer kinetic study was carried out by fitting the experimental breakthrough data in the Klinkenberg equation. The mass transfer coefficient of NaX granules was $1.3 \mathrm{~m} / \mathrm{s}$ and is higher than of the commercially available binderless $\mathrm{X}$ zeolite granules due to the creation of extra macroporosity by ice-templating in the freeze granulation process, making it an efficient structured material for a PSA unit in the biogas upgrading process with a fast uptake rate of $3.6 \mathrm{mg}$ of $\mathrm{CO}_{2} / \mathrm{g} / \mathrm{s}$.

Supplementary Materials: The following are available online, Figure $\mathrm{S} 1$ : $\mathrm{CO}_{2}$ breakthrough measurements on the commercial granules.

Author Contributions: Writing original draft, methodology, investigation, formal analysis, writing review and editing, K.N.; supervision, project administration, F.A. All authors have read and agree to the published version of the manuscript.

Funding: This research was funded by INNOVATION FUND DENMARK, grant number 5157-00008A.

Acknowledgments: The author acknowledges Juliette Guichard for her help in the freeze granulation processing.

Conflicts of Interest: The authors declare no conflict of interest. The funders had no role in the design of the study; in the collection, analyses, or interpretation of data; in the writing of the manuscript, or in the decision to publish the results.

\section{References}

1. Wang, J. Decentralized Biogas Technology of Anaerobic Digestion and Farm Ecosystem: Opportunities and Challenges. Front. Energy Res. 2014, 2, 1-12. [CrossRef]

2. Weiland, P. Biogas Production: Current State and Perspectives. Appl. Microbiol. Biotechnol. 2010, 85, 849-860. [CrossRef]

3. Baena-Moreno, F.; Rodrí-guez-Galán, M.; Vega, F.; Vilches, L.F.; Navarrete, B. Review: Recent Advances in Biogas Purifying Technologies. Int. J. Green Energy 2019, 16, 401-412. [CrossRef]

4. Singhal, S.; Agarwal, S.; Arora, S.; Sharma, P.; Singhal, N. Upgrading Techniques for Transformation of Biogas to Bio-CNG: A Review. Int. J. Energy Res. 2017, 41, 1657-1669. [CrossRef] 
5. Edwards, R.; Larive', J.; Weindorf, W. Well-to-Wheels Analysis of Future Automotive Fuels and Powertrains in the European Context; Institute of Energy and Transport, European Commission: Brussels, Belgium, 2011.

6. Augelletti, R.; Conti, M.; Annesini, M.C. Pressure Swing Adsorption for Biogas Upgrading. A New Process Configuration for the Separation of Biomethane and Carbon Dioxide. J. Cleaner Prod. 2017, 140, 1390-1398. [CrossRef]

7. Mel, M.; Ibrahim, M.M.A.; Setyobudi, R.H. Preliminary Study of Biogas Upgrading and Purification by Pressure Swing Adsorption. In AIP Conference Proceedings; AIP Publishing LLC: Melville, NY, USA, 2016.

8. Santos, M.P.S.; Grande, C.A.; Rodrigues, A.E. Pressure Swing Adsorption for Biogas Upgrading. Effect of Recycling Streams in Pressure Swing Adsorption Design. Ind. Eng. Chem. Res. 2011, 50, 974-985. [CrossRef]

9. Choi, S.; Drese, J.H.; Jones, C.W. Adsorbent Materials for Carbon Dioxide Capture from Large Anthropogenic Point Sources. ChemSusChem 2009, 2, 796-854. [CrossRef]

10. Bae, Y.; Snurr, R.Q. Development and Evaluation of Porous Materials for Carbon Dioxide Separation and Capture. Angew. Chem. Int. Ed. 2011, 50, 11586-11596. [CrossRef]

11. Samanta, A.; Zhao, A.; Shimizu, G.K.H.; Sarkar, P.; Gupta, R. Post-Combustion $\mathrm{CO}_{2}$ Capture using Solid Sorbents: A Review. Ind. Eng. Chem. Res. 2012, 51, 1438-1463. [CrossRef]

12. Cheung, O.; Wardecki, D.; Bacsik, Z.; Vasiliev, P.; McCusker, L.B.; Hedin, N. Highly Selective Uptake of Carbon Dioxide on the Zeolite $\left|\mathrm{Na}_{10.2} \mathrm{KCs}_{0.8}\right|-\mathrm{LTA}-\mathrm{A}$ Possible Sorbent for Biogas Upgrading. Phys. Chem. 2016, 18, 16080-16083. [CrossRef]

13. Jiang, Q.; Rentschler, J.; Sethia, G.; Weinman, S.; Perrone, R.; Liu, K. Synthesis of T-Type Zeolite Nanoparticles for the Separation of CO2/N2 and CO2/CH4 by Adsorption Process. Chem. Eng. J. 2013, 230, 380-388. [CrossRef]

14. Chen, C.; Park, D.; Ahn, W. $\mathrm{CO}_{2}$ capture using Zeolite 13 X Prepared from Bentonite. Appl. Surf. Sci. 2014, 292, 63-67. [CrossRef]

15. Gong, H.; Liu, W.; Liu, L.; Goyal, N.; Xiao, P.; Li, G.; Wei, Y.; Du, T. In-Situ Synthesis of an Excellent $\mathrm{CO}_{2}$ Capture Material Chabazite. J. Taiwan Inst. Chem. Eng. 2019, 103, 160-166. [CrossRef]

16. Liu, Z.; Grande, C.A.; Li, P.; Yu, J.; Rodrigues, A.E. Adsorption and Desorption of Carbon Dioxide and Nitrogen on Zeolite 5A. Sep. Sci. Technol. 2011, 46, 434-451. [CrossRef]

17. Database of Zeolite Structures. Available online: http://www.iza-structure.org/databases/ (accessed on 12 January 2020).

18. Akhtar, F.; Andersson, L.; Ogunwumi, S.; Hedin, N.; Bergström, L. Structuring Adsorbents and Catalysts by Processing of Porous Powders. J. Eur. Ceramic Soc. 2014, 34, 1643-1666. [CrossRef]

19. Alessandra, M. Structured Zeolite Adsorbents for PSA Applications. Ph.D. Thesis, Lulea University of Technology, Lulea, Sweden, November 2009.

20. Mosca, A.; Hedlund, J.; Ridha, F.N.; Webley, P. Optimization of Synthesis Procedures for Structured PSA Adsorbents. Adsorpt 2008, 14, 687-693. [CrossRef]

21. Zhang, W.; Narang, K.; Simonsen, S.B.; Vinkel, N.M.; Gudik-SÃ_rensen, M.; Han, L.; Akhtar, F.; Kaiser, A. Highly Structured Nanofiber Zeolite Materials for Biogas Upgrading. Energy Technol. 2019, 8, 10. [CrossRef]

22. Rezaei, F.; Webley, P. Structured Adsorbents in Gas Separation Processes. Sep. Purif. Technol. 2010, 70, 243-256. [CrossRef]

23. Ergun, S. Fluid Flow through Packed Columns. Chem. Eng. Prog. 1952, 48, 89-94.

24. Zhao, Z.; Cui, X.; Ma, J.; Li, R. Adsorption of Carbon Dioxide on Alkali-Modified Zeolite 13X Adsorbents. Int. J. Greenh. Gas Control 2007, 1, 355-359. [CrossRef]

25. Qian, L.; Zhang, H. Controlled Freezing and Freeze Drying: A Versatile Route for Porous and Micro-/Nano-Structured Materials. J. Chem. Technol. Biotechnol. 2011, 86, 172-184. [CrossRef]

26. Stuer, M.; Zhao, Z.; Bowen, P. Freeze Granulation: Powder Processing for Transparent Alumina Applications. J. Eur. Ceramic Soc. 2012, 32, 2899-2908. [CrossRef]

27. Jasra, R.V.; Tyagi, B.; Badheka, Y.M.; Choudary, V.N.; Bhat, T.S.G. Effect of Clay Binder on Sorption and Catalytic Properties of Zeolite Pellets. Ind. Eng. Chem. Res. 2003, 42, 3263-3272. [CrossRef]

28. Amir, C.; Mohammad, K.; Javad, A.S.; Sareh, A.A. Effect of Bentonite Binder on Adsorption and Cation Exchange Properties of Granulated Nano NaY Zeolite. Adv. Mater. Res. 2011, 335-336, 423-428.

29. Ouadaker, M.; Jiang, X.; Bowen, P.; Bienia, M.; Pagnoux, C.; Aimable, A. Porous Granules by Freeze Granulation of Pickering Emulsions Stabilized with Halloysite Particles. Colloids Surf. Physicochem. Eng. Aspects 2020, 585, 1-10. [CrossRef] 
30. Höhne, P.; Mieller, B.; Rabe, T. Slurry Development for Spray Granulation of Ceramic Multicomponent Batches. J. Ceram. Sci. Technol. 2018, 9, 327-336.

31. Deville, S. Freeze-Casting of Porous Biomaterials: Structure, Properties and Opportunities. Materials 2010, 3 , 1913-1927. [CrossRef]

32. Gutiérrez, M.C.; Ferrer, M.L.; Del Monte, F. Ice-Templated Materials: Sophisticated Structures Exhibiting Enhanced Functionalities obtained After Unidirectional Freezing and Ice-Segregation- Induced Self-Assembly. Chem. Mater. 2008, 20, 634-648. [CrossRef]

33. Lyckfeldt, O.; Rundgren, K.; Sjöstedt, M. Freeze Granulation for the Processing of Silicon Nitride Ceramics. Key Eng. Mat. 2004, 264, 281-284. [CrossRef]

34. Milne, S.J.; Mostaghaci, H. The Influence of Different Drying Conditions on Powder Properties and Processing Characteristics. Mater. Sci. Eng. A 1990, 130, 263-271. [CrossRef]

35. Ojuva, A.; Akhtar, F.; Tomsia, A.P.; Bergström, L. Laminated Adsorbents with very Rapid $\mathrm{CO}_{2}$ Uptake by Freeze-Casting of Zeolites. ACS Appl. Mater. Interfaces 2013, 5, 2669-2676. [CrossRef] [PubMed]

36. Sjöberg, M.; Bergström, L.; Larsson, A.; Sjöström, E. The Effect of Polymer and Surfactant Adsorption on the Colloidal Stability and Rheology of Kaolin Dispersions. Colloids Surf. A Physicochem. Eng. Asp. 1999, 159, 197-208. [CrossRef]

37. Dorado, F.; Romero, R.; Cañizares, P. Influence of Clay Binders on the Performance of Pd/HZSM-5 Catalysts for the Hydroisomerization of N-Butane. Ind. Eng. Chem. Res. 2001, 40, 3428-3434. [CrossRef]

38. Kim, D. Measurement of Point of Zero Charge of Bentonite by Solubilization Technique and its Dependence of Surface Potential on pH. Environ. Eng. Res. 2003, 8, 222-227. [CrossRef]

39. Akhtar, F.; Andersson, L.; Keshavarzi, N.; Bergström, L. Colloidal Processing and $\mathrm{CO}_{2}$ Capture Performance of Sacrificially Templated Zeolite Monoliths. Appl. Energy 2012, 97, 289-296. [CrossRef]

40. Bobić, B.M.; Miroslav, B.; Slobodan, M.; Ilija, B.; Milan, T.J. Experimental Investigation and Calculation of Shear Rate, Shear Stress and Power for Mixing of Semi-Solid Mixtures of ZA 27 Alloy and ZA 27/ $\mathrm{Al}_{2} \mathrm{O}_{3}$ Composites with Large $\mathrm{Al}_{2} \mathrm{O}_{3}$ Particles. In Changes; Association of Metallurgical Engineers of Serbia (AMES): Belgrade, Serbia, 2011.

41. Lowell, S.; Shields, J.E.; Thomas, M.A.; Thommes, M. Characterization of Porous Solids and Powders: Surface Area, Pore Size and Density; Springer: New York, NY, USA, 2006; pp. 11-14.

42. Sethia, G.; Somani, R.S.; Chand Bajaj, H. Adsorption of Carbon Monoxide, Methane and Nitrogen on Alkaline Earth Metal Ion Exchanged Zeolite-X: Structure, Cation Position and Adsorption Relationship. RSC Adv. 2015, 5, 12773-12781. [CrossRef]

43. Narang, K.; Fodor, K.; Kaiser, A.; Akhtar, F. Optimized Cesium and Potassium Ion-Exchanged Zeolites A and X Granules for Biogas Upgrading. RSC Adv. 2018, 8, 37277-37285. [CrossRef]

44. Thakkar, H.; Eastman, S.; Hajari, A.; Rownaghi, A.A.; Knox, J.C.; Rezaei, F. 3D-Printed Zeolite Monoliths for $\mathrm{CO}_{2}$ Removal from Enclosed Environments. ACS Appl. Mater. Interfaces 2016, 8, 27753-27761. [CrossRef]

45. Rezaei, F.; Mosca, A.; Webley, P.; Hedlund, J.; Xiao, P. Comparison of Traditional and Structured Adsorbents for $\mathrm{CO}_{2}$ Separation by Vacuum-Swing Adsorption. Ind. Eng. Chem. Res. 2010, 49, 4832-4841. [CrossRef]

46. García, L.; Poveda, Y.A.; Khadivi, M.; Rodrí-guez, G.; Görke, O.; Esche, E.; Godini, H.R.; Wozny, G.; Orjuela, A. Synthesis and Granulation of a 5A Zeolite-Based Molecular Sieve and Adsorption Equilibrium of the Oxidative Coupling of Methane Gases. J. Chem. Eng. Data 2017, 62, 1550-1557. [CrossRef]

47. García-Pérez, E.; Dubbeldam, D.; Maesen, T.L.M.; Calero, S. Influence of Cation Na/Ca Ratio on Adsorption in LTA 5A: A Systematic Molecular Simulation Study of Alkane Chain Length. J. Phys. Chem. B 2006, 110, 23968-23976. [CrossRef]

48. Moura, P.A.S.; Bezerra, D.P.; Vilarrasa-Garcia, E.; Bastos-Neto, M.; Azevedo, D.C.S. Adsorption Equilibria of $\mathrm{CO}_{2}$ and $\mathrm{CH}_{4}$ in Cation-Exchanged Zeolites 13X. Adsorpt 2016, 22, 71-80. [CrossRef]

49. Xue, Z.; Ma, J.; Hao, W.; Bai, X.; Kang, Y.; Liu, J.; Li, R. Synthesis and Characterization of Ordered Mesoporous Zeolite LTA with High Ion Exchange Ability. J. Mater. Chem. 2012, 22, 2532-2538. [CrossRef]

50. Chen, S.; Zhu, M.; Tang, Y.; Fu, Y.; Li, W.; Xiao, B. Molecular Simulation and Experimental Investigation of $\mathrm{CO}_{2}$ Capture in a Polymetallic Cation-Exchanged 13X Zeolite. J. Mater. Chem. A 2018, 6, 19570-19583. [CrossRef]

51. Naja, G.; Volesky, B. Behavior of the Mass Transfer Zone in a Biosorption Column. Environ. Sci. Technol. 2006, 40, 3996-4003. [CrossRef] 
52. Valdés-Solís, T.; Linders, M.J.G.; Kapteijn, F.; Marbán, G.; Fuertes, A.B. Adsorption and Breakthrough Performance of Carbon-Coated Ceramic Monoliths at Low Concentration of N-Butane. Chem. Eng. Sci. 2004, 59, 2791-2800. [CrossRef]

53. Ojuva, A.; Järveläinen, M.; Bauer, M.; Keskinen, L.; Valkonen, M.; Akhtar, F.; Levänen, E.; Bergström, L. Mechanical Performance and $\mathrm{CO}_{2}$ Uptake of Ion-Exchanged Zeolite A Structured by Freeze-Casting. J. Eur. Ceram. Soc. 2015, 35, 2607-2618. [CrossRef]

Sample Availability: Not available.

(C) 2020 by the authors. Licensee MDPI, Basel, Switzerland. This article is an open access article distributed under the terms and conditions of the Creative Commons Attribution (CC BY) license (http://creativecommons.org/licenses/by/4.0/). 